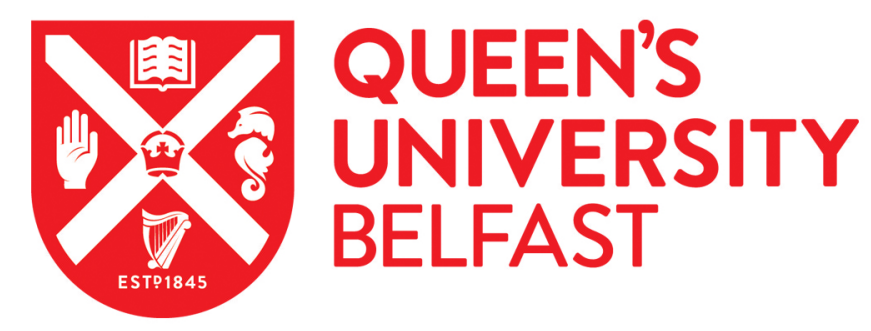

\title{
Developing techno-economically sustainable methodologies for deep desulfurization using hydrodynamic cavitation
}

Suryawanshi, N. B., Bhandari, V. M., Sorokhaibam, L. G., \& Ranade, V. V. (2017). Developing technoeconomically sustainable methodologies for deep desulfurization using hydrodynamic cavitation. Fuel, 210, 482490. https://doi.org/10.1016/j.fuel.2017.08.106

\section{Published in:}

Fuel

\section{Document Version:}

Peer reviewed version

Queen's University Belfast - Research Portal:

Link to publication record in Queen's University Belfast Research Portal

\section{Publisher rights}

Copyright 2017 Elsevier

This manuscript is distributed under a Creative Commons Attribution-NonCommercial-NoDerivs License

(https://creativecommons.org/licenses/by-nc-nd/4.0/), which permits distribution and reproduction for non-commercial purposes, provided the author and source are cited.

\section{General rights}

Copyright for the publications made accessible via the Queen's University Belfast Research Portal is retained by the author(s) and / or other copyright owners and it is a condition of accessing these publications that users recognise and abide by the legal requirements associated with these rights.

Take down policy

The Research Portal is Queen's institutional repository that provides access to Queen's research output. Every effort has been made to ensure that content in the Research Portal does not infringe any person's rights, or applicable UK laws. If you discover content in the Research Portal that you believe breaches copyright or violates any law, please contact openaccess@qub.ac.uk. 


\title{
Developing Techno-Economically Sustainable Methodologies for Deep Desulfurization using Hydrodynamic Cavitation
}

\author{
Nalinee B. Suryawanshi ${ }^{\mathrm{a}, \mathrm{b}}$, Vinay M. Bhandari ${ }^{\mathrm{a}, \mathrm{b} *}$, Laxmi Gayatri Sorokhaibam ${ }^{\mathrm{c}}$, Vivek $^{\mathrm{a}}$ \\ V. Ranade ${ }^{\mathrm{a}, 1}$ \\ ${ }^{a}$ Chemical Engineering and Process Development Division, CSIR-National Chemical \\ Laboratory, Pune-411 008, India \\ ${ }^{b}$ Academy of Scientific and Innovative Research (AcSIR), CSIR- National Chemical \\ Laboratory, Pune-411 008, India \\ ${ }^{c}$ Department of Chemistry, Visvesvaraya National Institute of Technology (VNIT) Nagpur, \\ Maharashtra-440010. India
}

\begin{abstract}
The present work, for the first time, describes the efficacy of the cavitation process and compares the cavitation yield for two types of cavitation devices- one employing linear flow for the generation of cavities and other employing vortex flow. The process involves preprogrammed mixing of the organic and aqueous phases, and can be carried out using simple mechanical cavitating devices such as orifice or vortex diode. The process essentially exploits in situ generation of oxidising agents such as hydroxyl radicals for oxidative removal of sulfur. The efficiency of the process is strongly dependent on the nature of device apart from the nature of the organic phase. The effects of process parameters and engineering designs were established for three organic solvents (n-octane, toluene, n-octanol) for model sulfur compound-Thiophene. A very high removal to the extent of $95 \%$ was demonstrated. The results were also verified using commercial diesel. The cavitation yield is significantly higher for vortex diode compared to the orifice. The process has potential to provide a green approach for
\end{abstract}

\footnotetext{
* Corresponding author:Email: vm.bhandari@ncl.res.in, (V. M. Bhandari)

${ }^{1}$ Present Address: School of Chemistry and Chemical Engineering, Queen's University Belfast, Northern Ireland, UK
} 
desulfurization of fuels or organics without the use of catalyst or external chemicals/reagents apart from newer engineering configurations for effective implementation of hydrodynamic cavitation in industrial practice and also appears to be economically sustainable.

Keywords: Fuel, Sulfur removal, Pollution control, Oxidation, Petroleum

\section{Introduction}

\subsection{Desulfurization}

Air pollution due to burning of fossil fuels is a major challenge and removal of sulfur from transportation fuels is an essential operation in petroleum refineries for reduced pollution due to SOx emission. The vehicular pollution in many major cities in many parts of the world has reached alarming proportion, forcing Governments worldwide to continuously enforce increasingly stricter norms for sulfur content in fuels for improved environmental sustainability. Euro-VI norms demand sulfur concentration in diesel and petrol to be less than $10 \mathrm{ppm}[1]$, compared to earlier norms of 350 and $500 \mathrm{ppm}$ in diesel and gasoline, subsequently lowered to the level of $15 \mathrm{ppm}$ and $30 \mathrm{ppm}$ in diesel and gasoline respectively[2-4]. Increased focus on newer developments such as fuel cell applications also demands more stringent limits on the sulfur levels (less than $1 \mathrm{ppm}$ ) to avoid poisoning of the catalyst. Biodiesel also can contain appreciable amounts of sulfur that requires processing in terms of sulfur reduction for sustainable applications[5].

The existing refinery operations have limitations with respect to satisfactory sulfur removal apart from the economics of the processes pertaining to the sulfur removal. There are a number of sulfur compounds in fuels that have varying concentrations and most importantly these vary in their reactivity as far as catalytic desulfurization is concerned demanding severe process conditions in terms of high temperature/pressures or newer catalysts. Conventional 
hydrodesulfurization (HDS) though suitable for lowering sulfur content up to $350 \mathrm{ppm}$, requires supplementary processes such as oxidation, adsorption or newer forms of processes that are capable of removing remaining refractory compounds to desired levels[6-8]. In view of the fact that huge volumes of fuels have to be processed techno-economically, there appears to be limited options for replacing the conventional HDS process that employs catalyst such as Co-Mo or Ni-Mo and requires high temperatures of the order of $450{ }^{0} \mathrm{C}$, along with high pressures of the order of 20-40 atm. Thus, it is apparent that though the HDS process can meet the new standards with certain modifications such as increased ( $\sim 3$ fold $)$ catalyst volume/reactor size and increased cost of operation, a more suitable practice would be to employ greener routes that can be integrated into the existing plant for better techno-economic feasibility and sustainability. The alternative can be in the form of adsorptive desulfurization using conventional adsorbents to $\pi$-complexation adsorbents[4,9-14], biodesulfurization[6,15] and oxidative desulfurization[16,17].Recently, oxidation processes in different forms have been increasingly discussed for desulfurization of fuels which also include processes that combine oxidation and extraction (Extractive and catalytic oxidative desulfurization or ECOD). In these, more thrust is placed on developing/ evaluating various catalysts for oxidation and suitable extractants for removing oxidation products[18-20]. Cavitation, which is also one form of advanced oxidation process, has also been discussed largely using catalysts for desulfurization. Commonly, ultrasound assisted oxidative desulfurization is reported in presence of various catalysts for different substrates[21-25], while hydrodynamic cavitation is rarely used, that too using catalyst such as hydrogen peroxide[26]. Different fuel fractions such as gasoline, jet fuel, and dieselhave different compounds from lower end compounds of sulphides, disulfides, mercaptans to refractory compounds such as thiophene, benzothiophene, dibenzothiophene and such alkylated derivatives of thiophene. Different desulfurization processes have a varying degree of success in removal of these varied forms of sulfur 
compounds and face severe challenges in the satisfactory and efficient removal of refractory sulfur compounds. Thiophene is one of the most difficult and refractory organic sulfur compound as far as oxidative desulfurization is concerned and hence its effective removal is crucial[27-29].

Recently, a non-catalytic process for deep desulfurization of fuels employing hydrodynamic cavitation with vortex diode for generating vortex flow for cavitation was reported[27] with a very high sulfur removal for thiophene. It is instructive to study, the impact of the engineering designs of cavitating devices and also evaluate techno-economic sustainability. In this work, the main objective is to report extensive studies on hydrodynamic cavitation for deep desulfurization of fuels and organics without employing any catalyst and under mild operating conditions, but using linear flow for cavitation, orifice as a cavitating device, compare the performance with that of vortex diode and finally evaluate economic feasibility. Thiophene was chosen as a model sulfur compound mainly due to the limitation of conventional oxidation processes in its removal[30] and also for ease of comparison of the different processes in this regard. Cavitational yields have been discussed in different forms of cavitation apart from establishing the applicability of cavitation method based on hydrodynamic cavitation for sulfur removal, especially by obtaining insight into the sulfur removal behaviour not just for different cavitating devices, but also for different process parameters, more importantly on the nature of organic phase by evaluating three different solvents viz. n-octanol, n-octane and toluene, apart from real diesel. We believe that the present route offers a greener and a sustainable approach to deep desulfurization of various fuels with significant ease of operation along with technoeconomic feasibility. 


\section{Experimental}

\subsection{Materials and Methods}

AR grade Thiophene was obtained from Sigma-Aldrich (>99\%). Organic solvents viz. nOctane (Lobachemie, 98\%), n-Octanol (Lobachemie, 99\%), Toluene (Merck, >99\%) and commercial diesel (obtained locally) were used as such for making the synthetic/model fuel. Sulfur analysis was carried out on Total Sulfur analyser TN-TS 3000 (Thermoelectron Corporation, Netherlands) and Gas chromatograph (Agilent 7890A) equipped with CPSil 5CB for sulfur as column $(30 \mathrm{~m} \times 320 \mu \mathrm{m} \times 4 \mu \mathrm{m})$ in conjunction with flame photometric detector (FPD) with Helium as a carrier gas, flow rate of $2 \mathrm{~mL} / \mathrm{min}$, split ratio of 10:1, Injector temperature of $250^{\circ} \mathrm{C}$, injection volume of $0.2 \mu \mathrm{L}$ and total analysis time of $25 \mathrm{~min}$. The oven temperature was ramped at $20^{\circ} \mathrm{C} / \mathrm{min}$ from $40^{\circ} \mathrm{C}$ to $100^{\circ} \mathrm{C}$ and at $60^{\circ} \mathrm{C} / \mathrm{min}$ from $100^{\circ} \mathrm{C}$ to $230^{\circ} \mathrm{C}$. Reproducibility of the experimental results was checked and was found satisfactory. Two different cavitating devices, orifice (single hole, $3 \mathrm{~mm}$ ) and vortex diode (66 mm chamber diameter) were employed for the cavitation studies.

\subsection{Experimental set-up}

The hydrodynamic cavitation process involves predefined mixing of sulfur containing organic phase with water under ambient conditions and pumping the mixture through the cavitating device such as orifice or vortex diode[31]. A schematic showing the different flow patterns in the two cavitating devices and the cavitation process is shown in Figure 1. In the inset of Figure 1, experimental set-up for the desulfurization studies is shown. Essentially, irrespective of the type of cavitating device, the cavitation process progresses through the formation, growth and implosion/collapse of the cavities and as a results of implosion, extreme temperatures $(\sim 10000 \mathrm{~K})$ and pressures $(\sim 1000 \mathrm{~atm})$ get generated at highly localized points of the cavity collapse, which consequently cleave water to generate, in situ, oxidising species such as 
hydroxyl radicals or hydrogen peroxide. Oxidation of the sulfur compounds is expected to take place under these conditions resulting in the removal of sulfur from the organics/ fuels, without actually employing any external catalyst/ reagent or externally employing high temperatures/pressures.

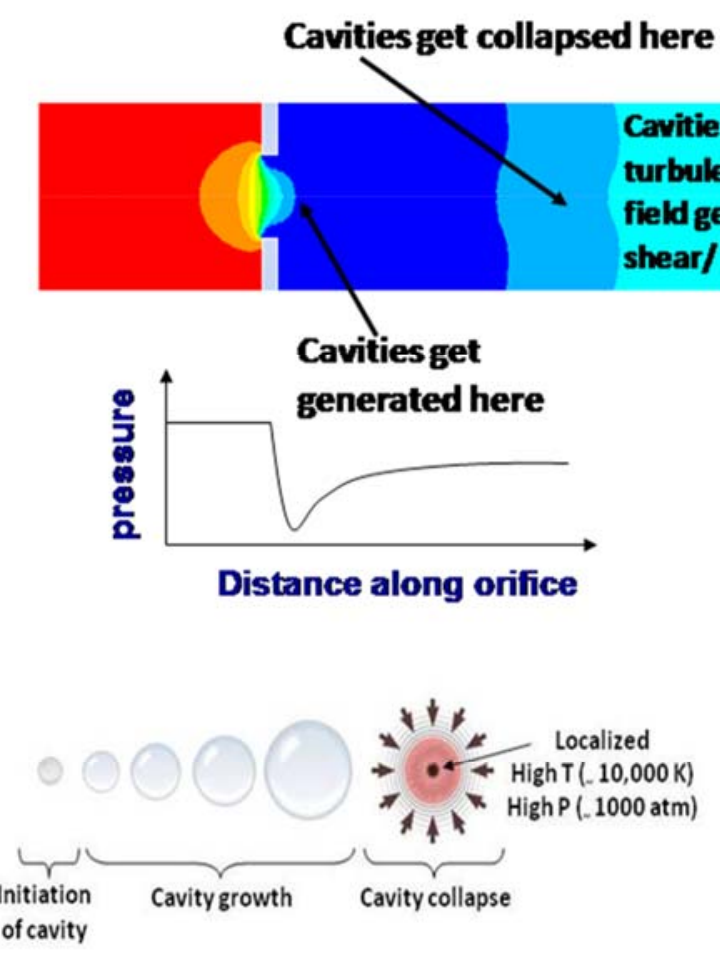

Oxidation of Sulfur Compounds due to Cavitation A qualitative comparison between Orifice \& Vortex Diode

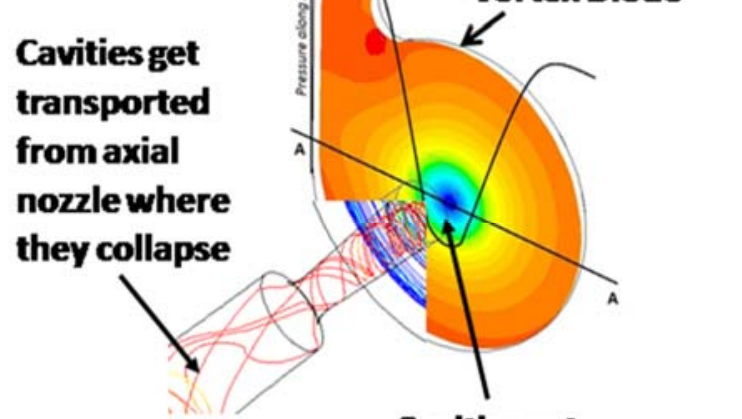

Cavities get generated here

Figure 1. Schematic representation of cavitation process in Orifice and Vortex Diode

A photograph of the experimental set-up for deep desulfurization using hydrodynamic cavitation is shown in the inset of Figure 1 indicating the two cavitation reactors namely orifice and vortex diode. The details of the set-up along with the schematic of experimental set-up and process flow sheet were given in our earlier report[27]. However, for immediate reference and clarity, some of the details are reproduced here. The experimental set-up (Stainless Steel SS 316) has different reactors as a cavitating device (nominal rated capacity, $1 \mathrm{~m}^{3} / \mathrm{h}$ ), a holding 
tank of $60 \mathrm{~L}$ capacity, high pressure vertical multistage centrifugal pump (China Nanfang Pump, Model CDLF 2-17; SS 316, 1000 LPH at 152 MWC, 2.2 kW, 2900 rpm, 415 V AC, 3 phase, $50 \mathrm{~Hz}$ motor), control valves and flow/ pressure and temperature controls. Flow transmitter (KROHNE, H250), pressure transmitters (Honeywell, ST700), Resistance Temperature Detector (RTD) (Eureka Engineering Enterprises, India) were used for the measurements. Typically 12-20 L volume was used for each experiment by appropriately measuring the organic (e.g. n-octanol, n-octane, toluene and commercial diesel) and aqueous phases. The initial sulfur content in the organic phase was adjusted to a predetermined concentration typically in the range of 100 to 300 ppm by adding known quantity of thiophene. The two-phase mixture: thiophene containing organic solvent and water, was then passed through the cavitating device e.g. orifice at a predetermined condition of pressure drop for any specific experiment. The sulfur concentration in the organic phase was measured at periodic intervals of time by separating the organic layer from the treated mixture. The experiments were typically carried out for $2 \mathrm{~h}$ and effect of various process parameters were studied for pressure drop in the range 2 to 10 bar, initial sulfur concentration( 100 to $300 \mathrm{ppm}$ ), organic phase volume ( $\%$ organic phase in the range 2.5 to $10 \%$ ) etc. The sulfur content was analysed in the organic phase using total sulfur analyser (TN-TS 3000 ) and the results were also crosschecked using gas chromatograph with FPD (Flame Photometric Detector) for sulfur analysis, as per the details mentioned in the earlier section.

\section{Results and Discussion}

\subsection{Identification of cavitation inception point in hydrodynamic cavitation}

It is essential that the cavitation process is performed for conditions of cavity generation, growth, and collapse. Identification of cavitation point is crucial in this regard, since above the cavitation point, cavitation is expected to take place and this information can be obtained using data pertaining to pressure drop measurements as a function of flow rate of two phase mixture 
(organic phase and water). The cavitation inception can be identified from the deviation of measured pressure drop from the usual square law $(\Delta \mathrm{P}$ proportional to the square of flow rate or mean velocity), as already established from the earlier studies for vortex diode and similar observations can be made for the orifice. From Figure 2, it is evident that while the cavitation inception in vortex diode occurs just before the pressure drop reaches 0.5 bar $(\sim 0.48$ bar), for orifice the inception of cavitation is at a substantially higher pressure drop and occurs at $\sim 1.25$ bar. The major cavitation effect is however seen at $\Delta \mathrm{P} 1.6$ bar or higher. In view of these observations, the experiments were carried out at a pressure drop across orifice at 2 bar and above ( 2 bar, 5 bar and 10 bar with a flow rate of $\sim 390,560$ and $785 \mathrm{LPH}$ ). 

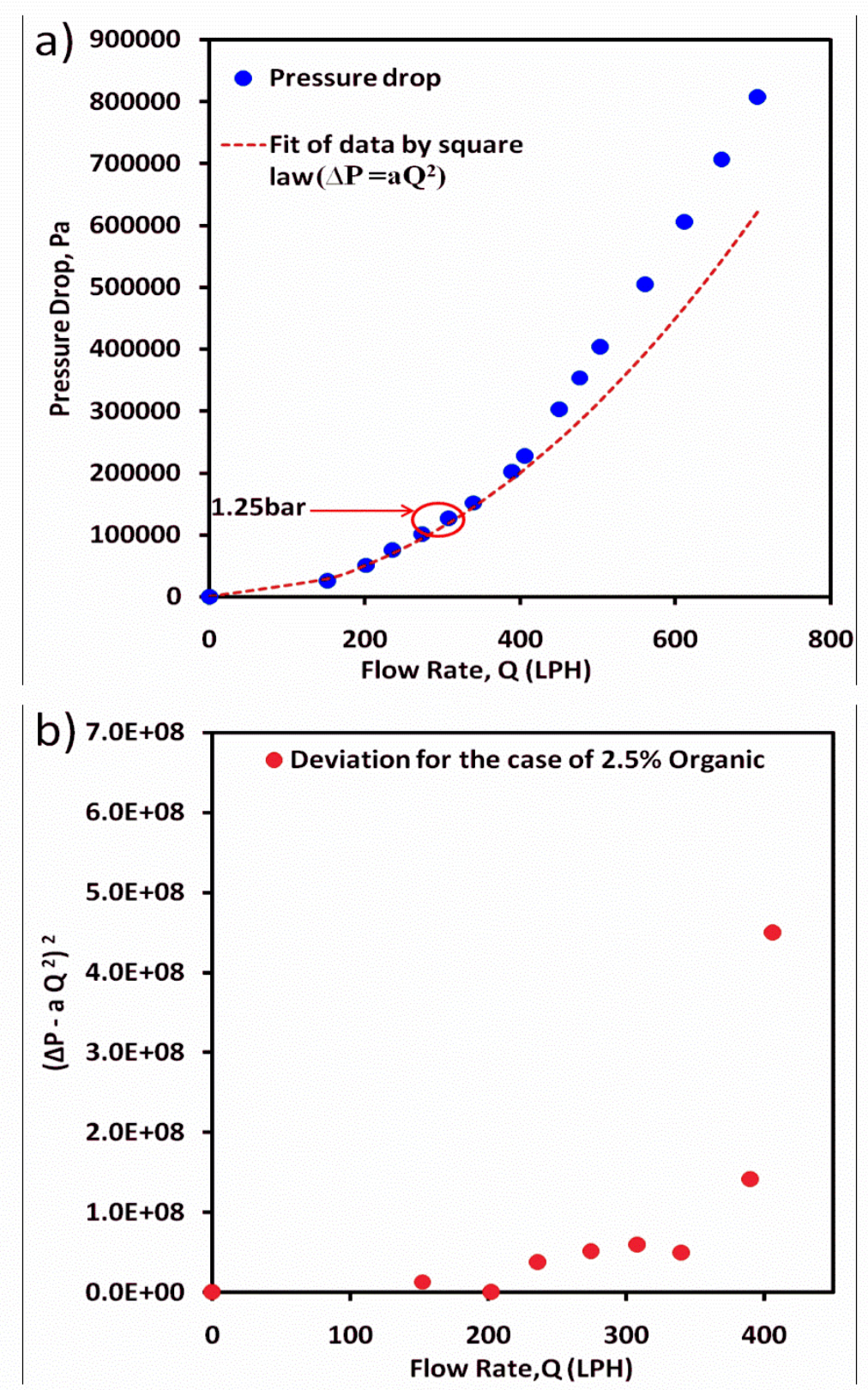

Figure 2. Inception of Cavitation - (a) Calculations to demonstrate cavitation occurring at a $\Delta \mathrm{P}$ of 1.25 bar (b) Prediction of inception of cavitation based on deviation from square law 3.2 Effect of pressure drop

The pressure drop across the orifice/ vortex diode or for that matter any cavitating device, is an important parameter that determines whether cavitation can take place and to what extent, apart from the cost of the operation. As is well established, the number density of cavities and intensity of cavity collapse are governed by the pressure drop across cavitating devices for a 
specified configuration of device and downstream design/piping. In order to establish the behaviour of desulfurization in the case of the orifice as against reported data on the vortex diode on desulfurization, experiments were carried out at three different pressure drop conditions, viz. 2, 5 and 10 bar. The results are shown in Figures3-4. Interestingly, similar to that reported for vortex diode, the effect of pressure drop was found to be rather negligible, especially at low values of organic to aqueous phase volume ratio.

It is evident from the Figure 3 and 4, the highest sulfur removal was observed to be above $90 \%$ at the pressure drop of 2 bar and 5 bar for $2.5 \%$ organic volume ( $\sim 92 \& 95 \%$ for n-Octanol), while for diesel it was $\sim 90 \%$ in 2 hours. A lower extent of removal ( $\sim 37 \%)$ was obtained for toluene as an organic phase under similar conditions. The effect of pressure drop is similar even when the organic volume is increased to $10 \%$. It appears that low to medium $\Delta \mathrm{P}$ values are satisfactory and removal efficiency can be significantly improved by using suitable organic solvent. The reason for this could be increased cavitation effect in the range of $\Delta \mathrm{P} 2$ to 5 bar, while above 5 bar $\Delta \mathrm{P}$, the cavities probably coalesce resembling choking which subsequently reduces the impact of cavitation. The overall effectiveness is proportional to the product of number of cavities and intensity of cavity collapse. Near the inception, cavity collapse intensity is higher since the medium is almost incompressible. However, number density of generated cavities is low. At very high pressure drop, though number density of cavities increases, the collapse intensity decreases significantly because of increased compressibility of the medium (due to the presence of a large number of bubbles). The overall effectiveness, therefore, exhibits maxima in terms of pressure drop. This aspect of cavitation in orifice is also evident from the analysis of Fig. 2 that deviation will continue to increase as flow rates (pressure drop) increase, however, the effect of cavitation will go from maxima since higher cavitation with higher flow rates (indicated by higher deviation) will lose effectiveness because of increased compressibility of the medium. 


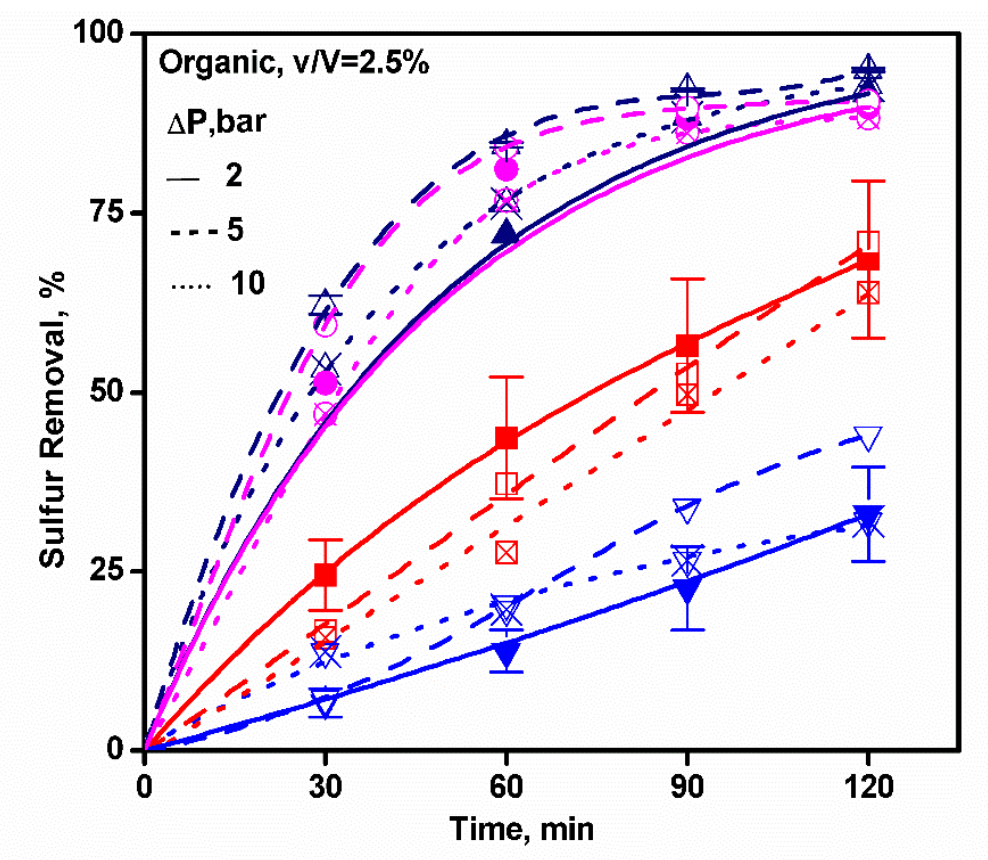

n-Octane,270ppm $\square$ n-Octane,300ppm $\otimes$ n-Octane,255ppm

$\Delta$ n-Octanol,290ppm $\triangle$ n-Octanol,312ppm n-Octanol,300ppm

$\nabla$ Toluene,270ppm $\nabla$ Toluene,295ppm \oluene,315ppm

- Diesel,320ppm $\bigcirc$ Diesel,385ppm $\otimes$ Diesel,320ppm

Figure 3. Effect of pressure drop at $2.5 \%$ organic volume fraction 


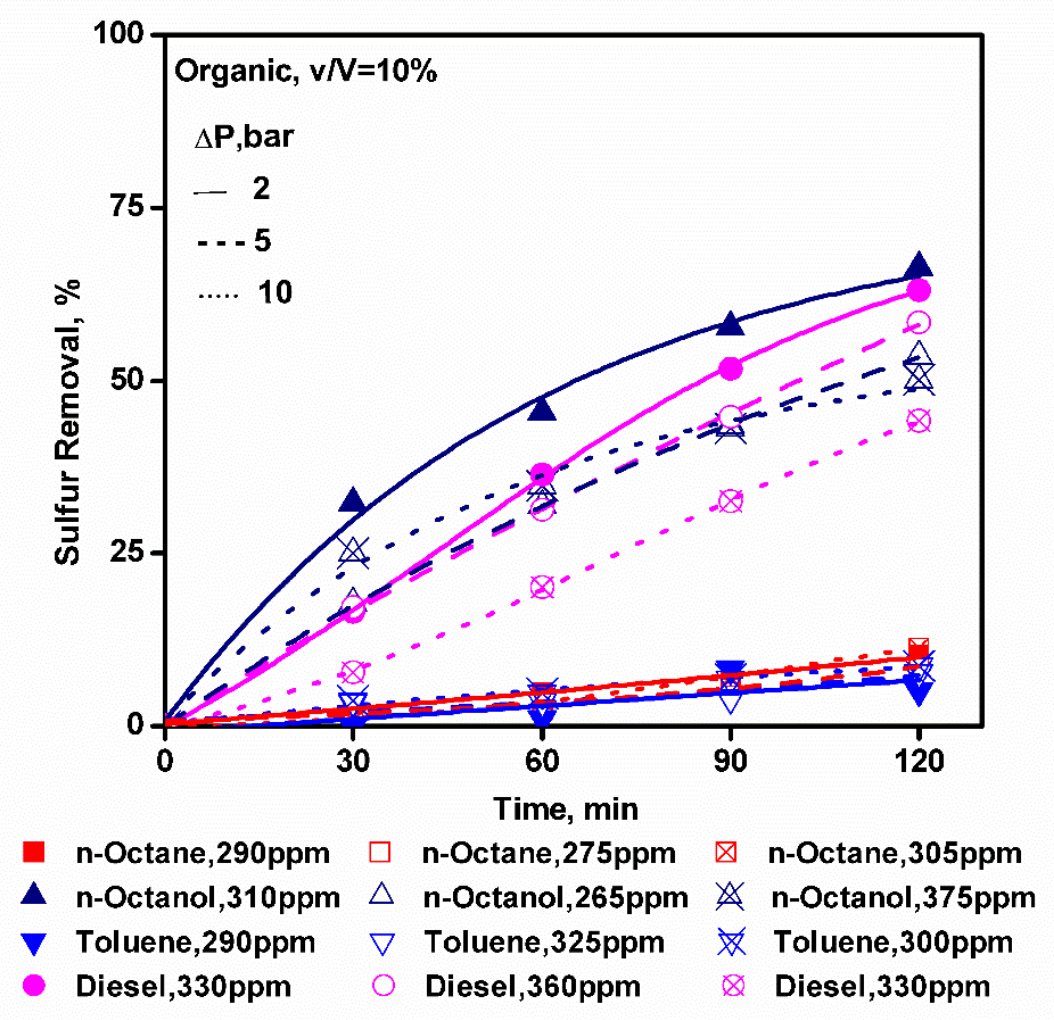

Figure4.Effect of pressure drop at $10 \%$ organic volume fraction

\subsection{Effect of initial sulfur concentration}

The initial sulfur concentrations in crude fractions can be very high, of the order of several thousand ppm as compared to processed fuel fractions such as gasoline or diesel which contain less than $300 \mathrm{ppm}$ for the existing streams, in general. The developed cavitation process is considered as complimentary to the existing refinery operations and hence higher concentration was considered of the order of $300 \mathrm{ppm}$ while lower concentration was considered at $\sim 100 \mathrm{ppm}$ to evaluate the effect of initial sulfur concentration. The results are shown in Figures 5 and 6 . It is evident that the effect of initial sulfur concentration is more significant in diesel as a solvent as compared to other organic solvents. Also, the initial high concentration of $300 \mathrm{ppm}$ shows better sulfur removal as compared to $100 \mathrm{ppm}$ for all the solvent systems indicating efficacy of hydrodynamic cavitation for satisfactory application, if combined with existing HDS process. The higher removal at the higher initial concentration may be due the increased probability of 
finding sulfur species for degradation. The overall rate of desulfurization is a function of concentration of S containing species and concentration of hydroxyl radicals. Exact mechanism of oxidative desulfurization occurring with the hydrodynamic cavitation is still not yet fully known. Desulfurization reactions may happen in gas phase (in the collapsing cavity) or in the liquid phase (after hydroxyl radicals diffuse in surrounding liquid from the collapsing cavity). In any of these scenarios, increase in concentration of S containing species will increase the overall rate and therefore overall extent of desulfurization. Again, the highest sulfur removal ( 95\%) was obtained for n-octanol and lowest for toluene. The intensity of the effect diminishes depending upon the nature of organic phase with the increase in the organic volume. Diesel consists of complex mixtures of aliphatic and aromatic hydrocarbons and the aromatic content can be typically in the range of $15-45 \%$. Therefore, the differences due to nature of solvent are believed to be largely due to aliphatic nature of the solvent, while polarity of the solvent could also have some contribution. This is, however, is a complex issue pertaining to the reactivity in different solvents and needs to be investigated in detail. The order of higher impact based on initial sulfur concentration for the organic solvents studied shows the following trend.

$$
\text { Diesel }>\text { n-Octanol }>\text { n-Octane }>\text { Toluene }
$$




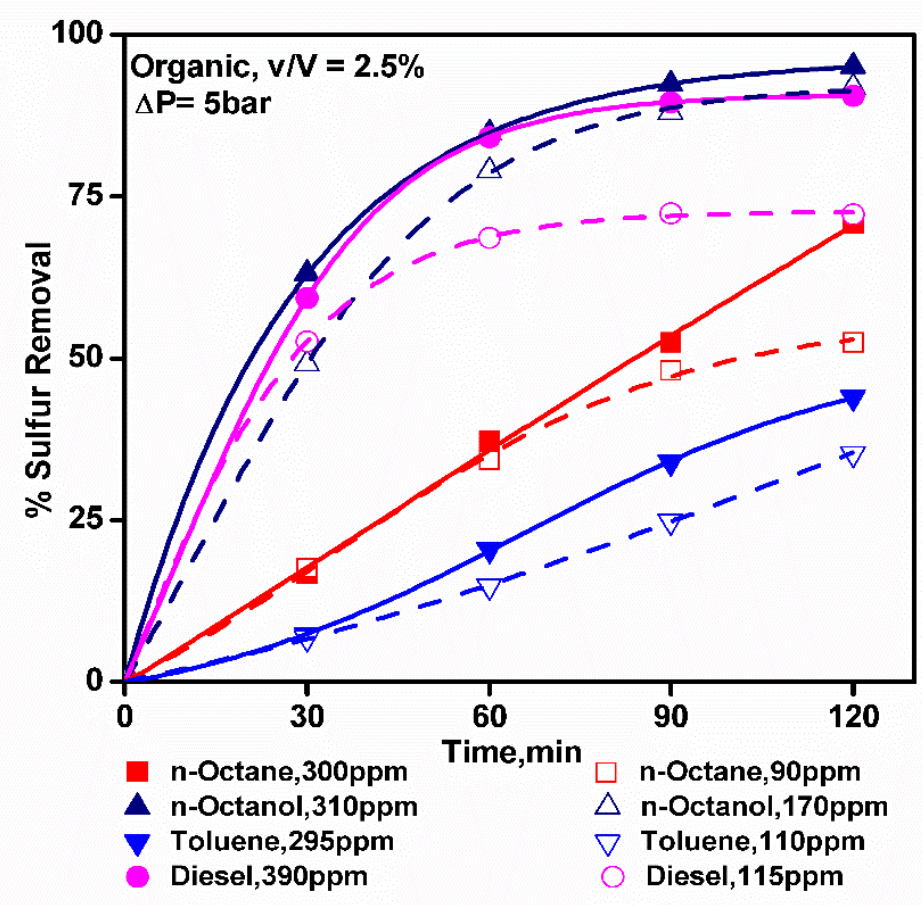

Figure 5. Effect of Initial concentration at 2.5\% organic volume

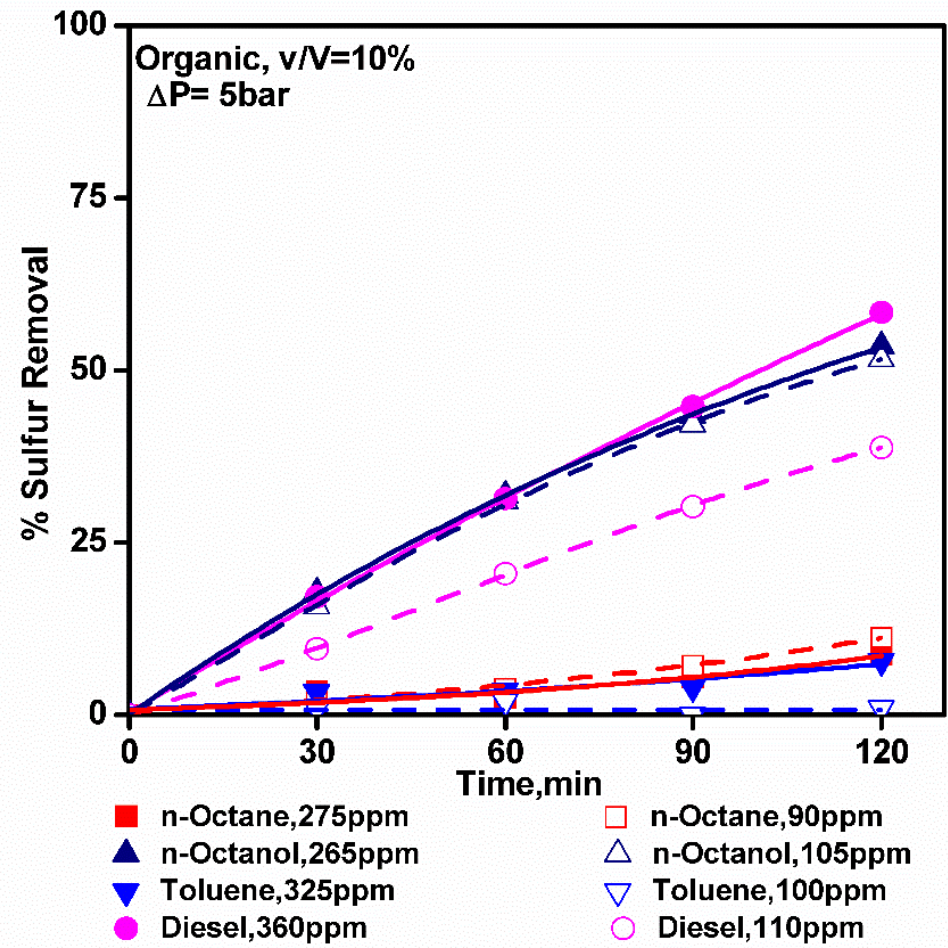

Figure 6. Effect of Initial concentration at 10\% organic volume 


\subsection{Effect of solvent phase ratio and nature of solvent}

The process scheme developed in this work envisages predefined mixing of the organic and aqueous phases with sulfur present in the organic phase. Thus, it is expected that the ratio of organic to aqueous phase would have a significant bearing on the efficiency of sulfur removal. Figures 7 and 8 show the results of the effect of the organic phase volume in terms of percentage volume of organic phase against the extent of sulfur removal. The two important observations are a low organic fraction $(2.5 \%)$ gives maximum sulfur removal while the nature of organic phase also playa important role in deciding sulfur removal efficiency. At $2.5 \%$ organic, $n-$

octanol and diesel shows almost equal percentage of sulfur removal at 300ppm initial concentration at all pressure drop conditions ( $90 \%)$. Sulfur removal in the case of $10 \% \mathrm{n}$ octanol is higher as compared to $10 \%$ diesel for all pressure drop conditions and both initial concentrations. The organic phase ratio indicates high sensitivity for all the solvents, except toluene and a lower ratio is favourable at any pressure condition, in general. The order for the increase/increment in sulfur removal efficiency for $2.5 \%$ organics can be given as:

n-Octane $>$ n-Octanol $\geq$ Diesel $>$ Toluene 


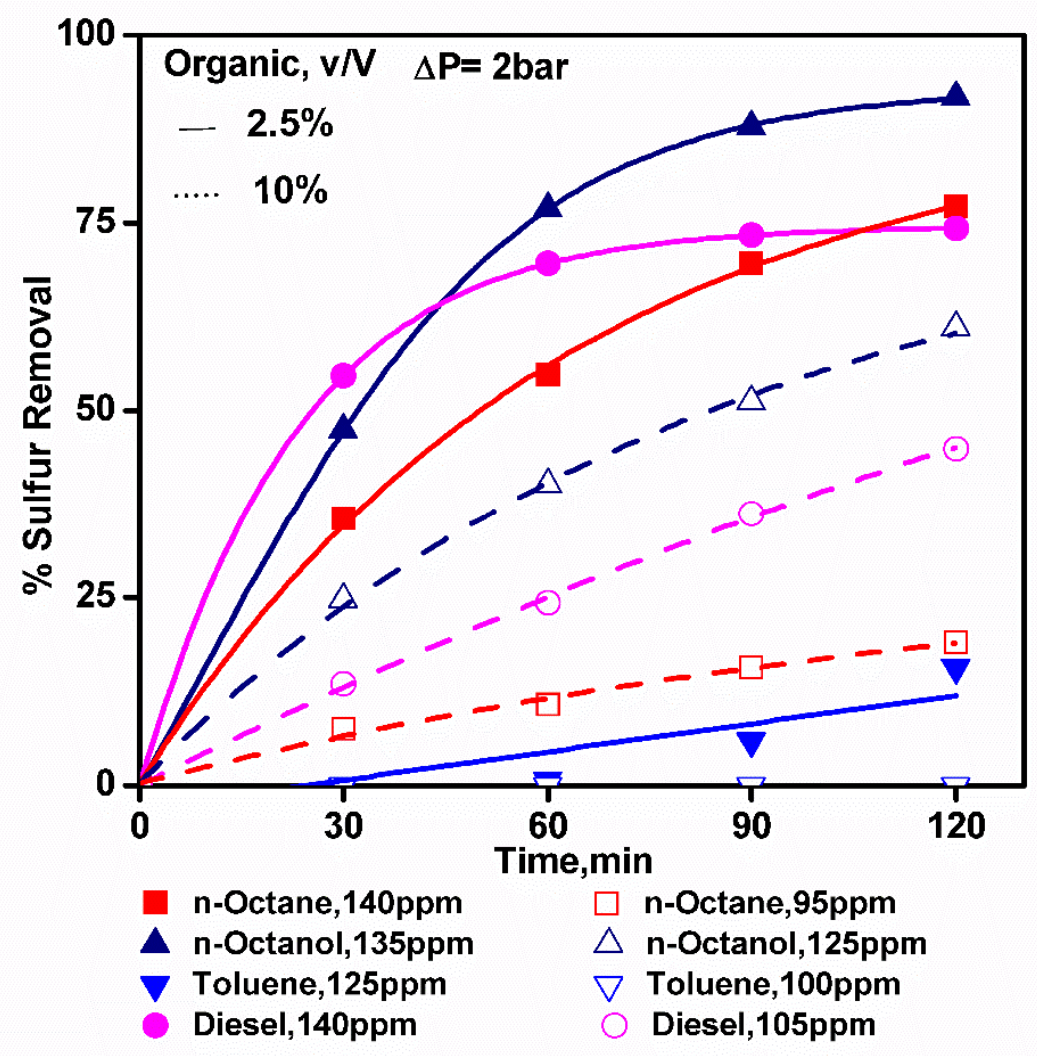

Figure 7. Effect of Organic Phase Ratio at Pressure drop, 2 bar 


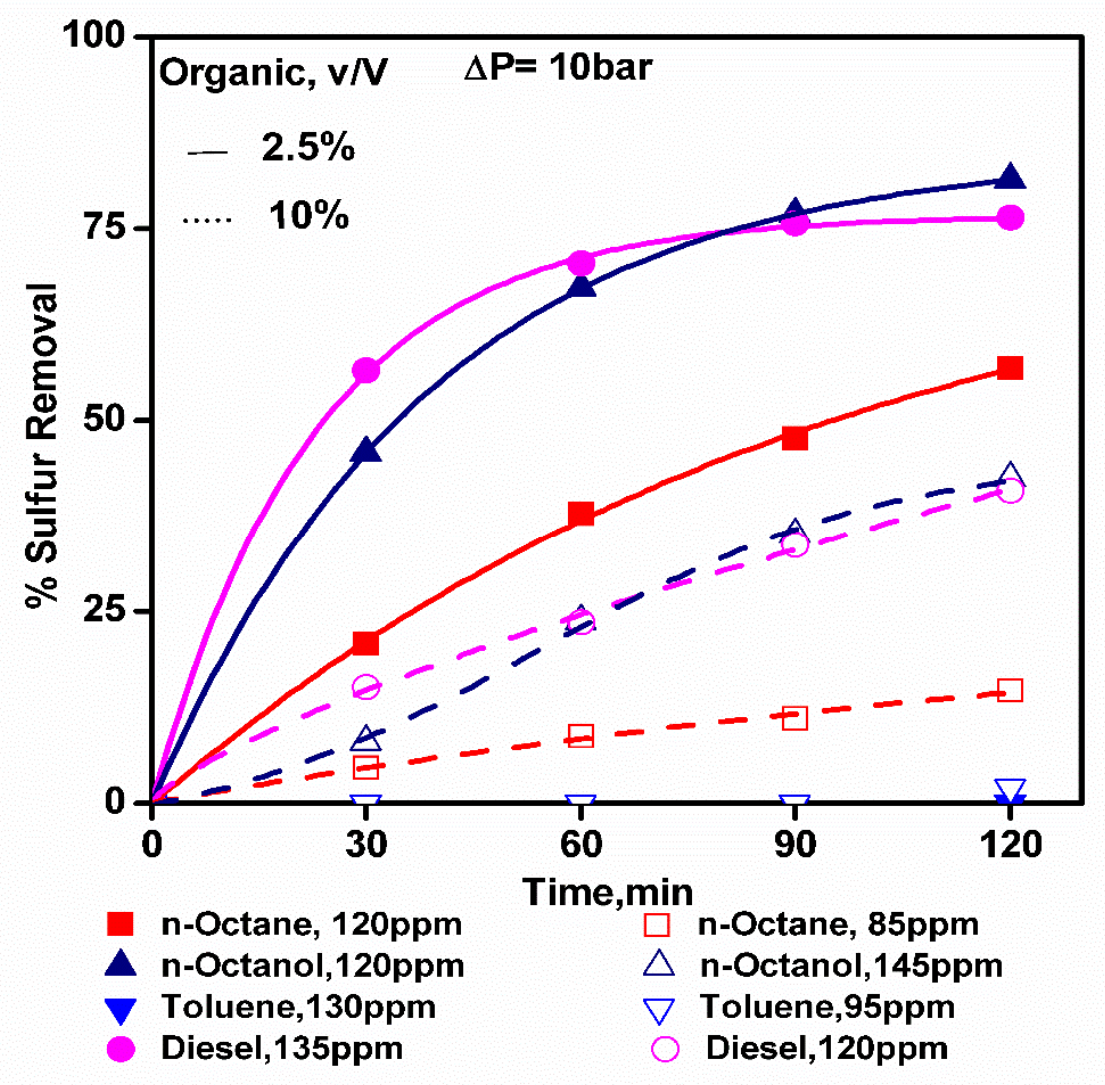

Figure 8. Effect of Organic Phase Ratio at Pressure drop, 10 bar

It appears that reducing the organic fraction increases the sulfur removal efficiency significantly, again depending on the nature of the solvent and for the case of initial sulfur concentration of $100 \mathrm{ppm}$ at 2 bar $\Delta \mathrm{P}$, the extent of improvement is given in Table- 1 . Toluene, as a solvent, indicated insensitivity in this regard and improvement was less significant even when the organic fraction was reduced from $10 \%$ to $2.5 \%$. This clearly indicates that the nature of organic phase has a very high impact on the sulfur removal efficiency.

Table-1: Extent of improvement in sulfur removal efficiency $(\Delta P=2$ bar; Initial sulfur conc. $100 \mathrm{ppm})$ 
Solvent

n-Octanol

Diesel

n-Octane

Toluene

92

\section{4}

77

15

The results of this work clearly indicate that nature of the organic phase is crucial in determining the efficiency of sulfur removal (n-Octanol $>$ Diesel $>$ n-Octane $>$ Toluene), which may be attributed to the aliphatic nature and polarity affecting reactivity during the oxidation reaction as mentioned earlier. Based on the dielectric constants, $\varepsilon$ (which is taken as a measure of solvent polarity, higher $\varepsilon$ signifying higher polarity), octanol may be considered to exhibit relatively polar character $(\varepsilon=10)$ while for toluene, diesel and n-octane, the $\varepsilon$ values are $2.4,2.2$ and 1.94 respectively [32,33]. The predominating factor (polarity/aliphatic/aromatic nature) under the extreme conditions of flash shockwaves is difficult to predict. Further, diesel being a complex mixture of hydrocarbons with its varying composition of aliphatic and aromatics, the oxidation chemistry is complex. However, the aliphatic nature of species such as n-octane may facilitate easy degradation while toluene is known to offer inhibition in oxidation due to the presence of $\pi$ conjugated aromatic system[34]. A postulated mechanism of cavitative degradation of sulphur compounds has the following important steps[27] :

1. Generation, growth and implosion of cavities due to hydrodynamic cavitation

2. Generation of oxidising agents such as hydroxyl radicals and hydrogen peroxide 


$$
\begin{array}{lll}
\mathrm{H}_{2} \mathrm{O} & \leftrightarrow & \mathrm{OH}^{\bullet}+\mathrm{H}^{\bullet} \\
\mathrm{O}_{2} & \rightarrow & 2 \mathrm{O}^{\bullet} \\
\mathrm{O}^{\bullet}+\mathrm{H}_{2} \mathrm{O} & \leftrightarrow & \mathbf{H O}^{\bullet} \\
\mathrm{H}^{\bullet}+\mathrm{O}_{2} & \rightarrow & \mathrm{HOO}^{\bullet} \\
2 \mathrm{HO}^{\bullet} & \rightarrow & \mathrm{H}_{2} \mathrm{O}_{2} \\
2 \mathrm{HOO}^{\bullet} & \rightarrow & \mathrm{H}_{2} \mathrm{O}_{2}+\mathrm{O}_{2}
\end{array}
$$

3. Reaction of thiophene and hydroxyl radicals/ oxidising agents and final degradation resulting into formation of water and $\mathrm{SO}_{2}$

$$
\begin{aligned}
& \text { Thiophene }+2 \mathrm{HO}^{\circ} \Rightarrow \mathrm{SO}_{2}+\mathrm{H}_{2} \mathrm{O} \\
& \text { Thiophene }+\mathrm{H}_{2} \mathrm{O}_{2} \Rightarrow \mathrm{SO}_{2}+\mathrm{H}_{2} \mathrm{O}
\end{aligned}
$$

The reaction of thiophene and hydroxyl radical resulting into the formation of water, intermediates and $\mathrm{SO}_{2}$ as suggested in our proposed mechanism are in line with the theoretical analysis of such reactions by Zhang et al. [35]. This conclusion has implications for the treatment of various organics for sulfur removal such as biodiesel and not just different fuel fractions. It is also essential to state that the nature of sulfur compounds is also expected to be critical in determining the process performance.

\subsection{Comparing cavitational yield for orifice and vortex diode}

Hydrodynamic cavitation works through the generation of hydroxyl radicals through cleaving of water molecules- an active oxidant. The in situ generation of oxidising agent participates in the oxidation of organics effecting their removal/degradation[36,37]. Though the mechanism for degradation of pollutants from water using cavitation is well discussed in the literature, there have not been any reports on the two phase/multiphase systems such as the one used in the present study. A plausible mechanism for the removal of sulfur[27]includes cleavage of the 
sulfur bond from the attack of oxidising agent and release of sulfur dioxide, while the formation of other products such as sulfones was largely unsubstantiated. In view of insolubility of the thiophene in water and the huge difference with respect to the organic solvent, the possibility of physical transfer of the thiophene in the aqueous phase is negligible. Thus, removal of sulfur is believed to be as $\mathrm{SO}_{2}$ and mineralization of the organic skeleton to final products as carbon dioxide and water. Again, it should also be possible for cavitation to work as a specific form of extractive, but not catalytic, oxidative desulfurization with water as a solvent and without employing any conventional catalyst of the type reported in the literature for ECOD. The other possibilities such as the formation of $\mathrm{SO}_{2}, \mathrm{HSO}_{3}, \mathrm{H}_{2} \mathrm{SO}_{4}$ etc. or organic species entering into the aqueous phase due to cavitation were not very relevant[27]. However, the formation of acid catalyst can certainly assist oxidative desulfurization[28,29], though, in the absence of an acid catalyst, the contribution of this mechanism may not be significant. Further, the nature and the number of cavities in vortex diode and in orifice could be substantially different and the exact mechanism appears to be much more complex and needs to be investigated in detail. It is believed that the role of solvent may be a facilitator in oxidative interfacial reactions for effecting the transfer of sulfur moiety in cavities housing oxidising species.

Kulkarni et al.[38] reported the velocity and pressure distribution in reverse flow vortex diode suggesting maximum pressure drop in reverse flow as compared to forward flow. Thus, in vortex diode, when the flow enters through the tangential port, a strong vortex flow gets created. As seen from Figure 1, in the vortex flow, tangential velocity increases towards the centre and pressure reduces at the centre with the color mappings indicating the different pressure/temperature regions. Strongly swirling flow generates a low pressure region at the centre of the vortex, extending into the axial port, which leads to cavitation[39] . As pressure is recovered in downstream-axial port then cavity collapse occurs that generates 
localized high shear, high temperature and pressure conditions and hydroxyl radicals. The orifice used in the present study is a simple single $3 \mathrm{~mm}$ diameter constriction which provides increased velocity head at the expense of pressure at the point as shown in Figure1. The trajectories of cavities and pressure history experienced by cavities in these two cavitation devices are quite different resulting in a different distribution of number density and collapse intensity of cavities. It will be instructive to evaluate the performance of vortex diode and orifice for desulfurization of fuels using the definition of cavitational yield which is given by equation 1 ,

$$
\text { CavitationalYield, } Y(\boldsymbol{m g} / J)=\frac{R}{\Delta P \times Q \times t}
$$

Where $\mathrm{R}$ is the amount of sulfur removed $(\mathrm{mg}), \Delta \mathrm{P}\left(\mathrm{N} / \mathrm{m}^{2}\right)$ is the pressure drop across the cavitation device, $\mathrm{Q}\left(\mathrm{m}^{3} / \mathrm{s}\right)$ is flow rate and $\mathrm{t}(\mathrm{s})$ is the time required for sulfur removal. Figure 9(a-d) shows the cavitational yield comparison for vortex diode and orifice.

It can be seen that there is a huge difference in the cavitational yield depending on the design of the cavitation reactor. As compared to that for orifice, the cavitational yield can be significantly higher for vortex diode and the impact is more prominent at high initial sulfur concentrations (e.g. $\mathrm{Y}=8.6 \times 10^{-4}, 1.17 \times 10^{-3}, 3.88 \times 10^{-4}$ for diode vs. $2.99 \times 10^{-4}, 3.33 \times 10^{-4}$ and $5.35 \times 10^{-5}$ for orifice in the case of n-octane, n-octanol, toluene respectively at initial concentration of $\sim 100 \mathrm{ppm}$ at $2.5 \%$ organic volume fraction). Similarly, the observed difference indicates $8,4,10$ and 4 times yield values with vortex diode for an initial sulfur concentration of $300 \mathrm{ppm}$ and $10 \%$ organic volume for n-octane, n-octanol, toluene, and diesel respectively. The reason for better cavitational yield in vortex diode can be attributed to the rotational flow in the axial port of vortex diode. The generated cavities and droplets of organic phase remain concentrated in the core of the axial port owing to their lower density compared to the water phase. This realizes significantly enhanced contact among cavities and organic droplets leading to better cavitational yield compared to orifice where no such preferential 
contact is realized. Although, the sulfur removal is increased at low organic volume fractions of $2.5 \%$, the difference in the cavitation yield here is somewhat less, $4,3 \& 2$ times for $n$ octane, n-octanol, and toluene respectively.
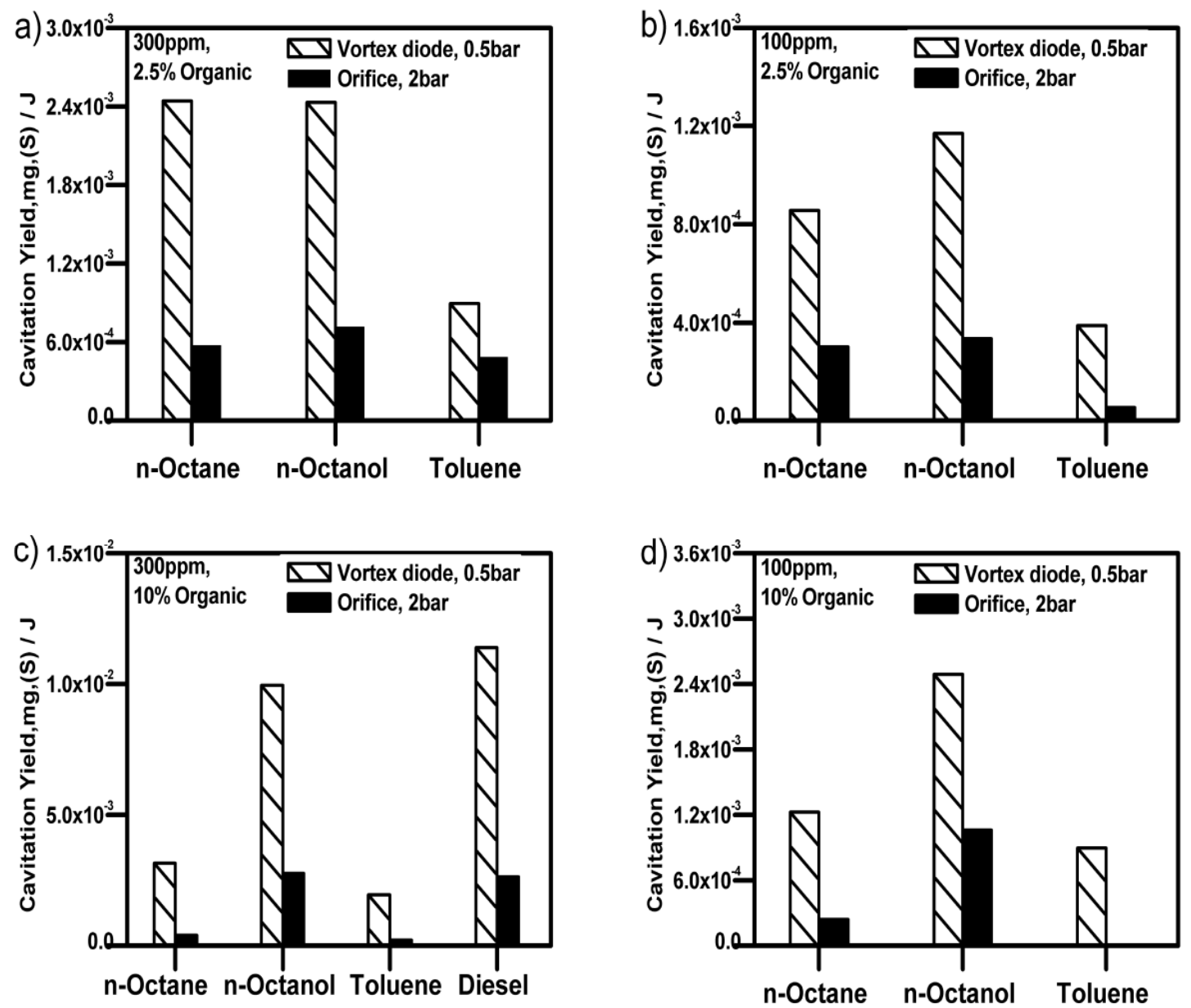

Figure9. Comparison of cavitational yield for vortex diode and orifice

\subsection{Comparing cost of desulfurization in different cavitating devices}

It is instructive to evaluate the cost of hydrodynamic cavitation using different devices from the commercial application point of view. The actual cost can be simply obtained by considering the cost of 1 electricity unit. Thus, the cost, $\mathrm{C}(\mathrm{kWh} / \mathrm{kg})$, can be simply related to the cavitational yield ' $\mathrm{Y}$ ' $(\mathrm{mg} / \mathrm{J})$ by equation 2 as: 


$$
C=\frac{1}{3.6 \sigma Y}
$$

Where, $\sigma$ is the efficiency of the pump. Assuming pump efficiency as 0.6 , we get $C=0.463 / Y$, $\mathrm{kWh} / \mathrm{kg}$. For example, if $\mathrm{Y}$ is 0.001 , we get $\mathrm{C}=463 \mathrm{kWh} / \mathrm{kg}$. In Indian scenario, assuming electricity price of $\sim$ Rs. $10 / \mathrm{kWh}$, the cost is less than Rs. $5000 / \mathrm{kg}$ of S removed which is quite attractive (A sample calculation of the cost is given in supplementary material, Annexure-1). The costs of desulfurization for two different devices and for different organic solvents are given in Figure 10 which also indicates the effect of concentration and solvent ratio on the cost. It can be seen that the cost is low for many solvents. It should be further noted that even when the efficiency of sulfur removal is lower for higher solvent volume fraction, in general (e.g. $10 \%$ compared to $2.5 \%$ ), the cost of sulfur removal is lower compared to low solvent volume fraction due to the processing of higher volume of organics. Thus, a compromise between sulfur removal efficiency and cost of processing is essential, apart from nature of the solvent. An extraordinarily low cost was obtained for an efficient solvent such as n-octanol and also for commercial diesel at $10 \%$ volume.

From Figure10, it is seen that the cost of desulfurization is substantially lower in the case of vortex diode as compared to the orifice, irrespective of processing parameters. This is also supported by the data of cavitational yields obtained for vortex diode as compared to the orifice. 


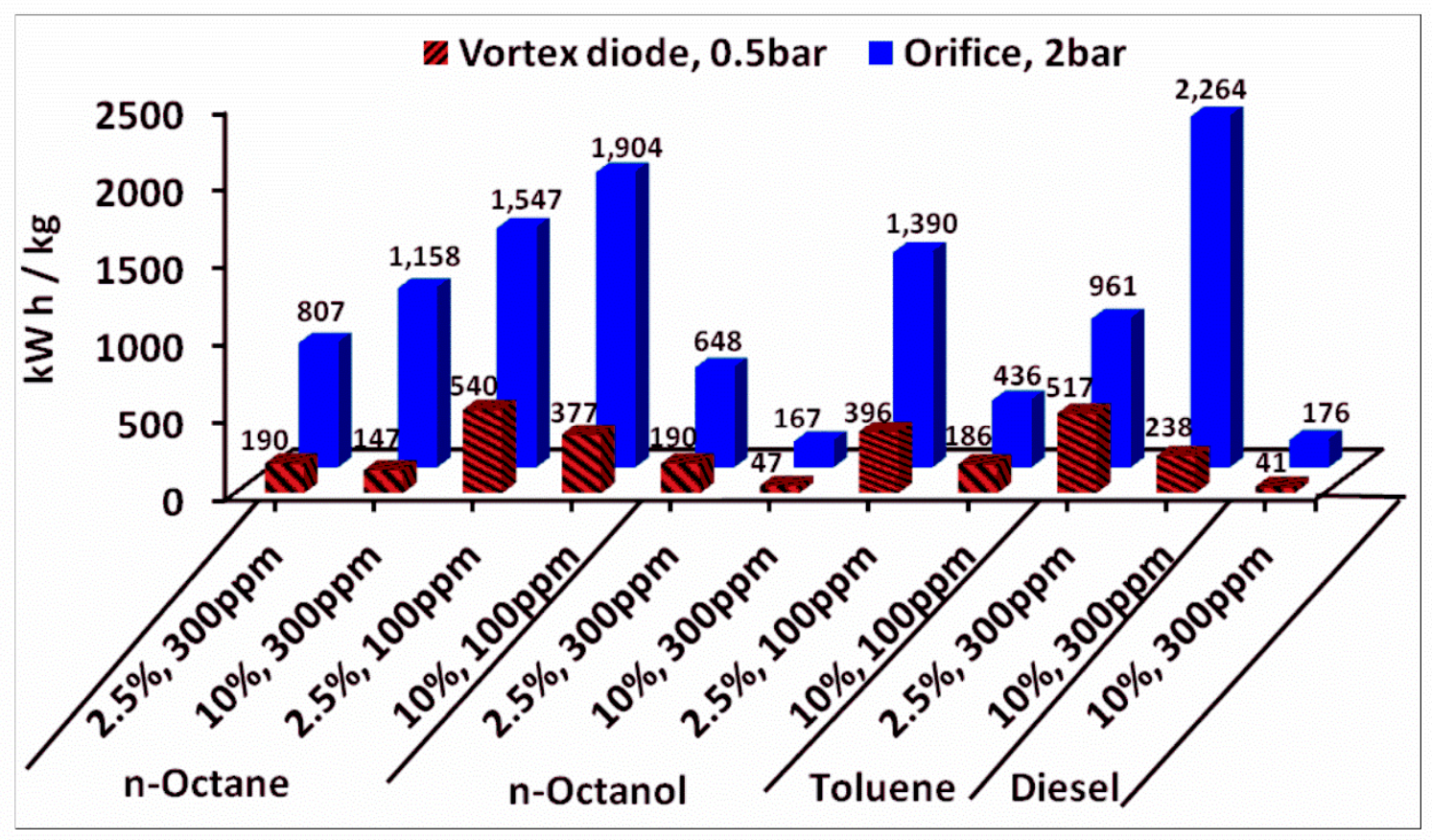

Figure 10.Representative cost/energy comparison for desulfurization using hydrodynamic cavitation for orifice and vortex diode

An approximate analysis of the cost comparison with other processes indicates operating cost of conventional hydrodesulfurization process for the removal of sulfur as $\$ 16.84 / \mathrm{kgS}[40]$. Typically the cost of commercial adsorbent varies in the range of $\$ 0.35 / \mathrm{kg}-20 \$ / \mathrm{kg}$. Considering sulfur selective adsorbent, even if the adsorbent cost is considered on the lower side at $\sim \$ 5 / \mathrm{kg}$ and capacity is assumed to be $30 \mathrm{mg} / \mathrm{g}$, the cost would be $\sim \$ 166 / \mathrm{kgS}$. In this comparison, the cost of hydrodynamic cavitation would be $\sim \$ 3 / \mathrm{kgS}$, significantly lower than both hydrodesulfurization and adsorptive desulfurization.

The finding of this work and the comparison between two cavitating devices clearly strengthen the premiss stated in our earlier work that the proposed method can be effectively employed to reduce the sulfur content of transportation fuels or other organic streams. As an engineering design, the aqueous phase can be recycled by appropriately adjusting the purge and make-up water. Further, the simplicity of the proposed method lies in the use of simple cavitating devices 
such as orifice or vortex diode, ease of operation, and compact set-up for effective removal of sulfur. Process intensification in the form of aeration or employing homogeneous/heterogeneous catalyst should also be possible. Therefore the method can be effectively implemented for large scale deep desulfurization operation, not just for fuels, but also for different organics.

\section{Conclusions}

A multiphase non-catalytic hydrodynamic cavitation process using orifice as a linear flow based cavitating device has been demonstrated for deep desulfurization of fuels or organics and the results have been compared with vortex diode as a vortex flow based cavitating device. The important conclusions can be listed as:

1. The inception of cavitation takes place at a significantly lower pressure drop in the case of vortex diode than that in the orifice. Thus, in vortex diode, the inception was found to occur at a pressure drop of $\sim 0.48$ bar as compared to higher pressure drop of $\sim 1.6$ bar in the case of orifice.

2. The non-catalytic hydrodynamic cavitation process can efficiently remove sulfur (thiophene ) from fuels for the cavitating devices such as orifice and vortex diode.

3. The process offers many advantages, most importantly ease of operation and mild operating conditions for effective sulfur removal.

4. The results on the sulfur removal confirm effect of solvent ratio and the nature of organics apart from pressure drop, and initial concentration of sulfur during the cavitation process.

5. The nature of the solvent has high impact on desulfurization and a very high sulfur removal was obtained for n-octanol and commercial diesel as organic phase.

6. The comparison of cavitational yield shows that the yield is nearly an order of magnitude higher in the case of vortex diode as compared to the orifice. 
7. The cost of desulfurization using hydrodynamic cavitation process was found to be quite low. Further, the operating cost is significantly lower in the case of vortex diode as compared to the orifice.

In view of the efficient sulfur removal from fuels accompanied by the low cost of operation, the proposed method can be considered as techno-economically sustainable alternative and can be effectively implemented for large scale deep desulfurization operations.

\section{Nomenclature}

C Cost of operation, $(\mathrm{kWh} / \mathrm{kg})$

P Pressure, (bar; $\mathrm{N} / \mathrm{m}^{2}$ )

$\mathrm{R} \quad$ Amount of sulfur removed, (mg)

Rs. Indian rupees

Q Flow rate, $\left(\mathrm{LPH} ; \mathrm{m}^{3} / \mathrm{s}\right)$

$\mathrm{T}$ Temperature, $(\mathrm{K})$

$\mathrm{t} \quad$ Time, $(\mathrm{s})$

$\mathrm{V} \quad$ Volume, $\left(\mathrm{m}^{3}\right)$

$\mathrm{V} \quad$ Total volume, $\left(\mathrm{m}^{3}\right)$

Y Cavitational yield, $(\mathrm{mg} / \mathrm{J})$

$\Delta \mathrm{P} \quad$ Pressure drop, (bar; $\mathrm{N} / \mathrm{m}^{2}$ )

$\sigma \quad$ Efficiency of pump

\section{AUTHOR INFORMATION}

*Corresponding Author: Tel: +91 2025902171; Fax: +91 2025893041.

E-mail: vm.bhandari@ncl.res.in (V.M. Bhandari)*

laxmigayatri1@gmail.com (LaxmiGayatri Sorokhaibam)

nb.suryawanshi@ncl.res.in (Nalinee B. Suryawanshi)

V.Ranade@qub.ac.uk (Vivek V. Ranade)

¥Present address: School of Chemistry and Chemical Engineering, Queen's University Belfast, Northern Ireland, UK 


\section{Notes:}

The authors declare no competing financial interest.

\section{Acknowledgements}

The authors wish to acknowledge financial support from IndusMagic (CSC0123) and SETCA (CSC0113) for the research program of this work. Ms. Nalinee Suryawanshi acknowledges Council of Scientific and Industrial Research (CSIR) fellowship, Government of India for this work.

\section{References}

[1] EPA. EPA Proposes Tier 3 Motor Vehicle Emission and Fuel Standards Regulatory Announcement 2. 2013.

[2] Bhandari VM, Ko CH, Park JG, Han SS, Cho SH, Kim JN. Desulfurization of diesel using ionexchanged zeolites. Chem Eng Sci 2006;61:2599-608. doi:10.1016/j.ces.2005.11.015.

[3] Song C. An overview of new approaches to deep desulfurization for ultra-clean gasoline, diesel fuel and jet fuel. Catal Today 2003;86:211-63. doi:10.1016/S0920-5861(03)00412-7.

[4] Yang RT. Desulfurization of Transportation Fuels with Zeolites Under Ambient Conditions. Science (80- ) 2003;301:79-81. doi:10.1126/science.1085088.

[5] Ma H, Addy MM, Anderson E, Liu W, Liu Y, Nie Y, et al. A novel process for low-sulfur biodiesel production from scum waste. Bioresour Technol 2016;214:826-35. doi:10.1016/j.biortech.2016.05.029.

[6] Song C, Ma X. New design approaches to ultra-clean diesel fuels by deep desulfurization and deep dearomatization. Appl Catal B Environ 2003;41:207-38. doi:10.1016/S09263373(02)00212-6.

[7] Chandra Srivastava V. An evaluation of desulfurization technologies for sulfur removal from liquid fuels. RSC Adv 2012;2:759. doi:10.1039/c1 ra00309g.

[8] Huang Y, Zhou Z, Qi Y, Li X, Cheng Z, Yuan W. Hierarchically macro-/mesoporous structured Co-Mo-Ni/??-A12O3 catalyst for the hydrodesulfurization of thiophene. Chem Eng J 2011;172:444-51. doi:10.1016/j.cej.2011.06.006.

[9] Dai W, Zhou Y, Wang S, Su W, Sun Y, Zhou L. Desulfurization of transportation fuels targeting at removal of thiophene/benzothiophene. Fuel Process Technol 2008;89:749-55. doi:10.1016/j.fuproc.2008.01.002.

[10] Chica A, Strohmaier K, Iglesia E. Adsorption, desorption, and conversion of thiophene on HZSM5. Langmuir 2004;20:10982-91. doi:10.1021/la048320.

[11] Li CJ, Li YJ, Wang JN, Zhao L, Cheng J. Ag+-loaded polystyrene nanofibrous membranes preparation and their adsorption properties for thiophene. Chem Eng J 2013;222:419-25. doi:10.1016/j.cej.2012.09.107.

[12] Sorokhaibam LG, Bhandari VM, Salvi MS, Jain S, Hadawale SD, Ranade V V. Development of Newer Adsorbents: Activated Carbons Derived from Carbonized Cassia fistula. Ind Eng Chem Res 2015;54:11844-57. doi:10.1021/acs.iecr.5b02945.

[13] Hernández-Maldonado AJ, Yang RT. Desulfurization of commercial liquid fuels by selective adsorption via $\pi$-complexation with $\mathrm{Cu}(\mathrm{I})$-Y zeolite. Ind Eng Chem Res 2003;42:3103-10. doi:10.1021/ie0301132.

[14] Ania CO, Parra JB, Arenillas A, Rubiera F, Bandosz TJ, Pis JJ. On the mechanism of reactive adsorption of dibenzothiophene on organic waste derived carbons. Appl Surf Sci 2007;253:5899-903. doi:10.1016/j.apsusc.2006.12.065.

[15] Soleimani M, Bassi A, Margaritis A. Biodesulfurization of refractory organic sulfur compounds in fossil fuels. Biotechnol Adv 2007;25:570-96. doi:10.1016/j.biotechadv.2007.07.003.

[16] Caero LC, Hernández E, Pedraza F, Murrieta F. Oxidative desulfurization of synthetic diesel using supported catalysts: Part I. Study of the operation conditions with a vanadium oxide 
based catalyst. Catal Today 2005;107:564-9. doi:10.1016/j.cattod.2005.07.017.

[17] Abdalla ZEA, Li B. Preparation of MCM-41 supported (Bu4N)4H3(PW11O39) catalyst and its performance in oxidative desulfurization. Chem Eng J 2012;200-202:113-21. doi:10.1016/j.cej.2012.06.004.

[18] Mirhoseini H, Taghdiri M. Extractive oxidation desulfurization of sulfur-containing model fuel using hexamine-phosphotungstate hybrid as effective heterogeneous catalyst. Fuel 2016;167:60-7. doi:10.1016/j.fuel.2015.11.042.

[19] Zheng D, Zhu W, Xun S, Zhou M, Zhang M, Jiang W, et al. Deep oxidative desulfurization of dibenzothiophene using low-temperature-mediated titanium dioxide catalyst in ionic liquids. Fuel 2015;159:446-53. doi:10.1016/j.fuel.2015.06.090.

[20] Timko MT, Wang JA, Burgess J, Kracke P, Gonzalez L, Jaye C, et al. Roles of surface chemistry and structural defects of activated carbons in the oxidative desulfurization of benzothiophenes. Fuel 2016;163:223-31. doi:10.1016/j.fuel.2015.09.075.

[21] Jin L, Cao Q, Li J, Dong J. Sulfur removal in coal tar pitch by oxidation with hydrogen peroxide catalyzed by trichloroacetic acid and ultrasonic waves. Fuel 2011;90:3456-60. doi:10.1016/j.fuel.2011.06.047.

[22] Wu Z, Ondruschka B. Ultrasound-assisted oxidative desulfurization of liquid fuels and its industrial application. Ultrason Sonochem 2010;17:1027-32. doi:10.1016/j.ultsonch.2009.11.005.

[23] Bhasarkar JB, Chakma S, Moholkar VS. Mechanistic features of oxidative desulfurization using sono-fenton-peracetic acid (ultrasound/Fe2+-CH3COOH-H 2O2) system. Ind Eng Chem Res 2013;52:9038-47. doi:10.1021/ie400879j.

[24] Bhasarkar JB, Singh M, Moholkar VS. Mechanistic insight into phase transfer agent assisted ultrasonic desulfurization. RSC Adv 2015;5:102953-64. doi:10.1039/C5RA12178G.

[25] Mei H, Mei BW, Yen TF. A new method for obtaining ultra-low sulfur diesel fuel via ultrasound assisted oxidative desulfurization. Fuel 2003;82:405-14. doi:10.1016/S00162361(02)00318-6.

[26] OlegV. Kozyuk, N. Ridgeville O. Desulfurization Process and Systems Utilizing Hydrodynamic Cavitation. US8002971 B2, 2011.

[27] Suryawanshi NB, Bhandari VM, Sorokhaibam LG, Ranade V V. A Non-catalytic Deep Desulphurization Process using Hydrodynamic Cavitation. Nat Publ Gr 2016. doi:10.1038/srep33021.

[28] Otsuki S, Nonaka T, Takashima N, Qian W, Ishihara A, Imai T, et al. Oxidative Desulfurization of Light Gas Oil and Vacuum Gas Oil by Oxidation and Solvent Extraction. Energy \& Fuels 2000;14:1232-9. doi:10.1021/ef000096i.

[29] Chen T-C, Shen Y-H, Lee W-J, Lin C-C, Wan M-W. Optimization of Thiophene Removal by an Ultrasound-Assisted Oxidative Desulfurization Process. Environ Eng Sci 2012;29:623-9. doi:10.1089/ees.2011.0123.

[30] Lin F, Wang DG, Jiang ZX, Ma Y, Li J, Li RG, et al. Photocatalytic oxidation of thiophene on BiVO4 with dual co-catalysts $\mathrm{Pt}$ and $\mathrm{RuO} 2$ under visible light irradiation using molecular oxygen as oxidant. Energy Environ Sci 2012;5:6400-6. doi:10.1039/c1ee02880d.

[31] Bhandari VM, Ranade V V, Suryawanshi NB. Novel process for desulfurization of fuels and organics. 2015-INV-0092: 0230NF2015, 2015.

[32] Dean JA. LANGE'S HANDBOOK OF CHEMISTRY. 15th ed. New York: McGRAW-HILL; 1999.

[33] De Souza JE, Scherer MD, Cáceres JAS, Caires ARL, M'Peko J-C. A close dielectric spectroscopic analysis of diesel/biodiesel blends and potential dielectric approaches for biodiesel content assessment. Fuel 2013;105:705-10. doi:10.1016/j.fuel.2012.09.032.

[34] Yashnik SA, Salnikov A V., Kerzhentsev MA, Saraev AA, Kaichev V V., Khitsova LM, et al. Effect of the nature of sulfur compounds on their reactivity in the oxidative desulfurization of hydrocarbon fuels with oxygen over a modified CuZnAlO catalyst. Kinet Catal 2017;58:5872. doi:10.1134/S0023158417010128.

[35] Zhang Y, Sun J, Sun Y, Tang Y, Wang R. Mechanistic and kinetic study on the reaction of thiophene with hydroxyl radical. Comput Theor Chem 2016;1092:74-81.

doi:10.1016/j.comptc.2016.08.002. 
[36] Bhandari VM, Sorokhaibam LG, Ranade V V. Industrial wastewater treatment for fertilizer industry - A case study. Desalin Water Treat 2016;57:1-11.

[37] Saharan VK, Pinjari D V., Gogate PR, Pandit AB. Chapter 3 - Advanced Oxidation Technologies for Wastewater Treatment: An Overview. Ind. Wastewater Treat. Recycl. Reuse, 2014, p. 141-91. doi:10.1016/B978-0-08-099968-5.00003-9.

[38] Kulkarni AA, Ranade V V., Rajeev R, Koganti SB. CFD simulation of flow in vortex diodes. AIChE J 2008;54:1139-52. doi:10.1002/aic.11439.

[39] Priestman GH. A Study of Vortex Throttles Part 2: Viscid Flow Analysis. Proc Inst Mech Eng Part C J Mech Eng Sci 1987;201:337-43. doi:10.1243/PIME_PROC_1987_201_132_02.

[40] Mares-Davila FI, Green J, Terashima J, Omotinugbon T, Mares-Davila FI, Green J, et al. THE HYDRODESULFURIZATION OF DIESEL FUEL TO MEET NEW EPA REQUIREMENTS. The University of Arizona., 2016.

TOC

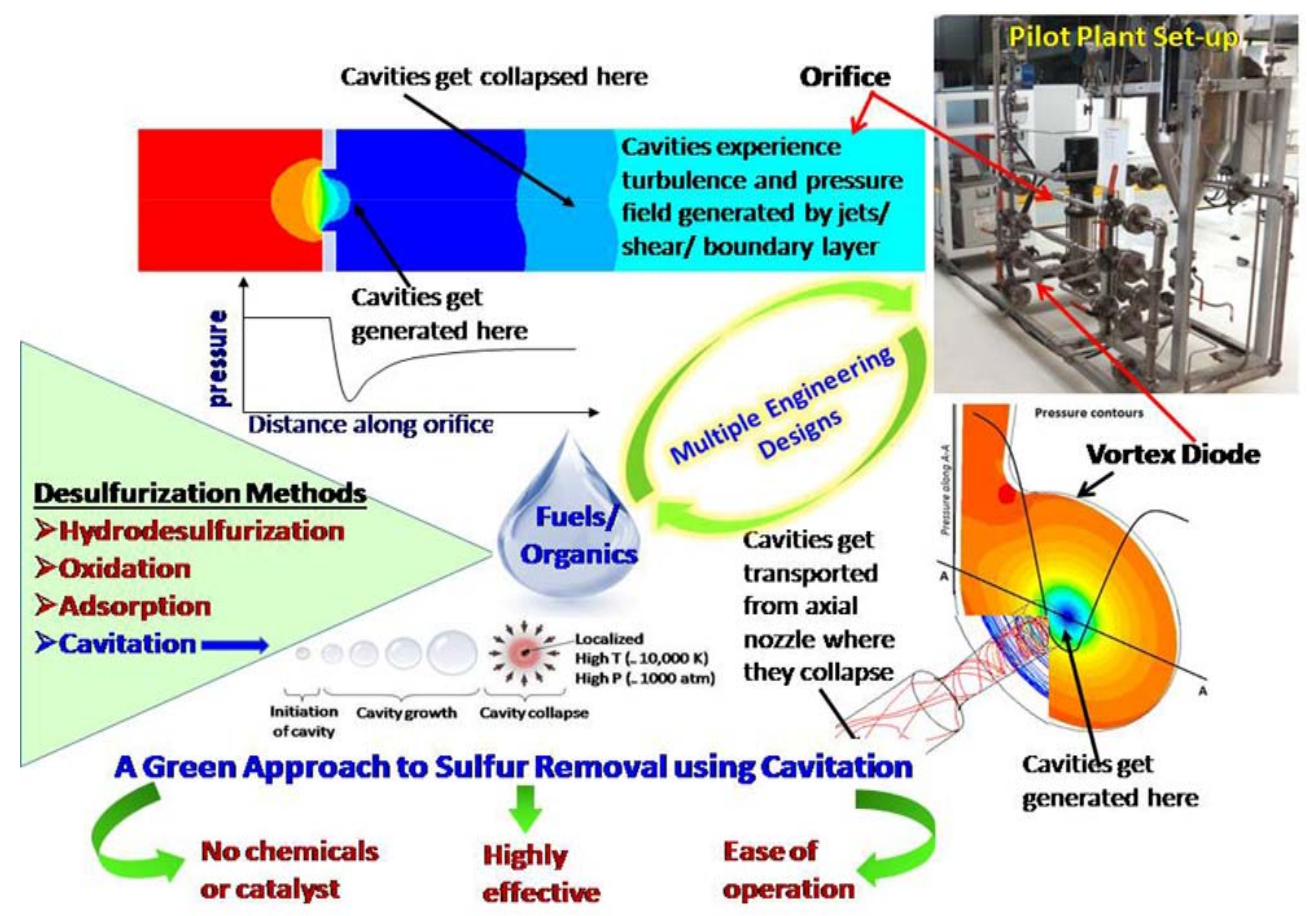

TOC synopsis

Green alternatives for sulfur removal from fuels / organics with potential to techno-economically alter existing desulfurization practices with ease of operation. 
